This item was submitted to Loughborough's Research Repository by the author.

Items in Figshare are protected by copyright, with all rights reserved, unless otherwise indicated.

\title{
Microstructural analysis of steam oxidation of IN617 for use in ultra- supercritical steam plants
}

PLEASE CITE THE PUBLISHED VERSION

PUBLISHER

(c) Maney Publishing.

VERSION

AM (Accepted Manuscript)

LICENCE

CC BY-NC-ND 4.0

\section{REPOSITORY RECORD}

Gorman, David M., Rebecca L. Higginson, H. Du, G. McColvin, A.T. Fry, and Rachel C. Thomson. 2014.

"Microstructural Analysis of Steam Oxidation of IN617 for Use in Ultra-supercritical Steam Plants". figshare. https://hdl.handle.net/2134/15325. 
This item was submitted to Loughborough's Institutional Repository (https://dspace.lboro.ac.uk/) by the author and is made available under the following Creative Commons Licence conditions.

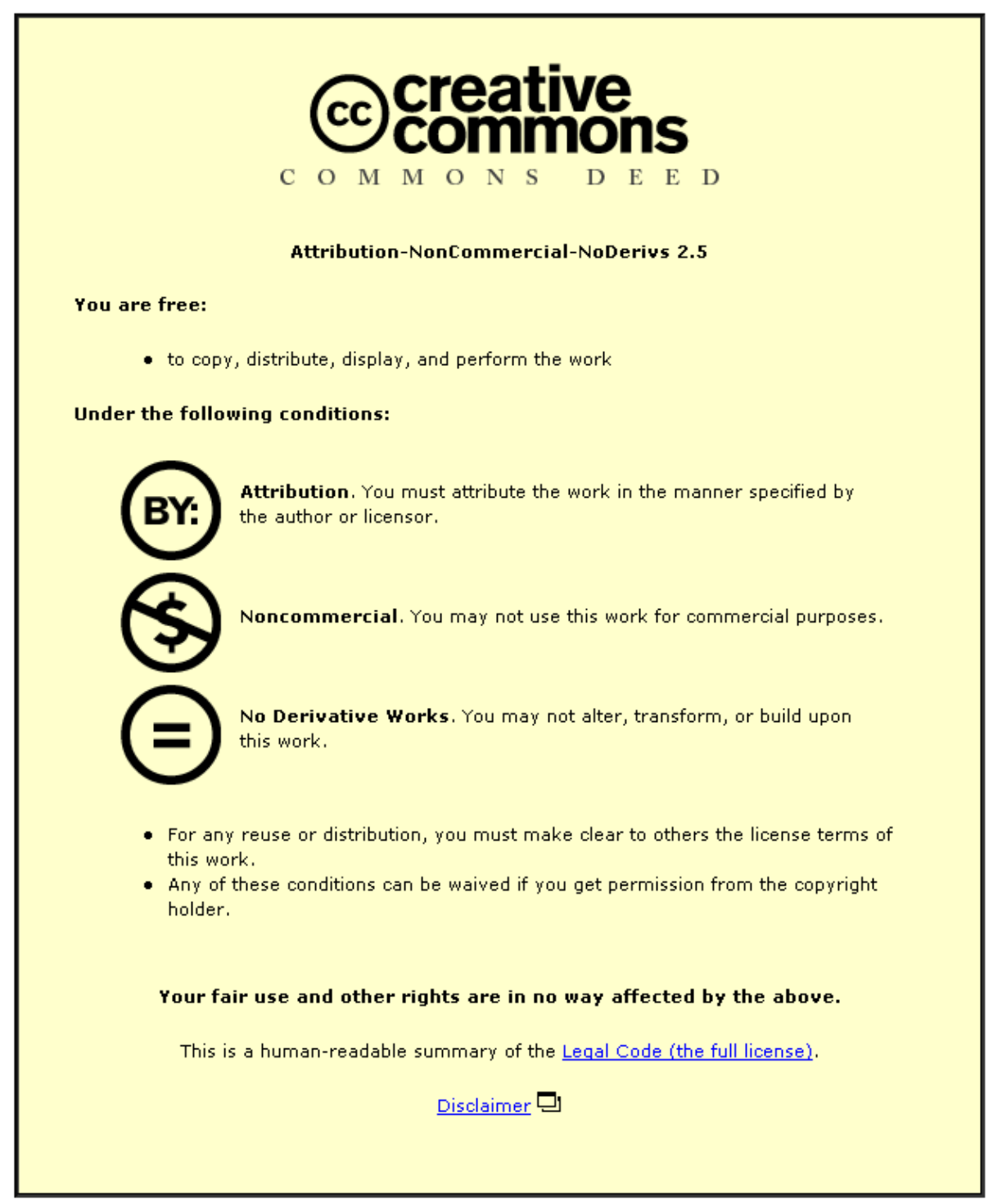

For the full text of this licence, please go to: http://creativecommons.org/licenses/by-nc-nd/2.5/ 


\title{
Microstructural Analysis of Steam Oxidation of IN617 for use in Ultra-Supercritical Steam Plants
}

\author{
D. M. Gorman ${ }^{1}$, R. L. Higginson ${ }^{1}$, Hailiang Du ${ }^{2}$, Gordon McColvin ${ }^{2}$ \\ A. T. Fry ${ }^{3}$ and R. C. Thomson ${ }^{1}$ \\ ${ }^{1}$ Department of Materials, Loughborough University, Loughborough, Leicestershire, LE11 $3 T U$ \\ ${ }^{2}$ Alstom Power Ltd., Newbold Road, Rugby, Warwickshire, CV21 2NH \\ ${ }^{3}$ National Physical Laboratory, Hampton Road, Teddington, Middlesex, TW11 OLW
}

\begin{abstract}
The microstructural evolution of IN617 subjected to oxidising atmospheres of $100 \%$ steam, $50 \%$ steam/argon and air in the temperature range $700-750^{\circ} \mathrm{C}$ for exposures times up to $4,000 \mathrm{~h}$ at atmospheric pressure has been investigated using a range of analytical electron microscopy techniques. It has been found that for this alloy the presence of steam in the atmosphere has an effect on the oxidation kinetics, and influences the nature of the scale. It has also been shown that there are differences in the volume and nature of voids formed, and that the voids are often associated with an internal structure of alumina. Significant internal oxidation was observed, particularly in the presence of steam, and a 3D reconstruction of the microstructure using FIBSEM techniques showed that this comprised of interconnected alumina plates which followed the grain boundaries into the substrate.
\end{abstract}

\section{Introduction}

A major step towards the UK's goals of reducing carbon emissions can be made by improving the efficiency of steam driven power plant. One route to achieving an improvement in efficiency involves increasing the operating conditions of the working steam. The typical operating conditions in coal fired power plants in the hottest regions of the subcritical steam cycle are $\sim 540^{\circ} \mathrm{C} / \sim 175$ bar. State-ofthe-art ultra-supercritical $\left(275 \mathrm{bar} / 600^{\circ} \mathrm{C} / 620^{\circ} \mathrm{C}\right)$ are offered today where the required material properties are already well established. Further efficiency increases of 8-10\% points may be possible with the adoption of cost effective and functional materials available for long term use capable of withstanding temperatures and pressures in excess of $700^{\circ} \mathrm{C}$ and 300 bar. One possible avenue to achieve this is to use nickel based alloys, which are well known for their high creep strength and resistance to corrosion at high temperatures. One such candidate material is IN617, which is a well established alloy which already finds use in numerous applications in the nuclear, waste incineration 
and gas turbine industries, all of which require excellent mechanical properties and very good oxidation/corrosion resistance at elevated temperatures.

It is generally understood that the presence of steam affects the oxidation processes of steel and a number of other metal alloys [1,2]. Alterations in these oxidation processes can increase the rate of scale formation and/or alter the nature of the scale that is formed. For example, in ferritic steels with a Cr content above 9 wt.\%, a transition occurs from the formation of magnetite-based oxides in air to Cr-rich oxides in steam which results in a reduction in the rate of oxidation [3]. A review by Saunders et al concluded that the presence of steam impacts multiple aspects of oxide growth including adsorption, dissociation, oxide volatilisation and diffusion of reactants when compared to similar processes in dry conditions [4]. Oxidation in the presence of steam also affects the mechanical properties of the scale. There have been mixed results on the effects of steam on scale adherence, although an increase in the rate of scale formation in steam will lead to thicker scales and in turn increase the likelihood of spallation, especially when combined with thermal cycling [4].

Much of the literature mentions a lack of available data on the effects of steam on the oxidation process, especially when considering nickel based alloys. However, a recent review comments that there is a large amount of work involving laboratory exposures and boiler loop tests currently being conducted in large programs in Europe, Japan and the US [1]. At this point it is worth noting that there is an effort to move away from standard isothermal laboratory oxidation experiments to include variables such as thermal cycling, heat flux, high pressure environments, steam flow, coupon geometry, coupon thickness etc, to allow for better comparisons to be made between laboratory exposures and in situ observations made in industrial situations.

This research is concerned with IN617 that has been oxidised under isothermal conditions at atmospheric pressure in $100 \%$ steam, $50 / 50 \%$ steam/argon and also in air atmospheres in the temperature range $700-750^{\circ} \mathrm{C}$ for up to 4000 hours. The techniques employed in this investigation are Scanning Electron Microscopy (SEM), Energy Dispersive X-ray Spectroscopy (EDX), Transmission Electron Microscopy (TEM) and Focussed Ion Beam Scanning Electron Microscopy 
(FIBSEM) which have all been used to produce a quantitative analysis of some of the key features of the oxidation of IN617, and to investigate the effects of different atmospheric conditions involving steam on the oxidation mechanism.

\section{Experimental Methods}

The nominal composition of IN617 is shown in Table 1. The IN617 was received in rod form before being cut down into disks approximately $2 \mathrm{~mm}$ thick and between $15-25 \mathrm{~mm}$ in diameter. Each disk was prepared by grinding to 600 grit on $\mathrm{SiC}$ paper and cleaned using industrial alcohol prior to exposure. The range of sample oxidation conditions are shown in Table 2.

Table 1. Nominal composition of IN617 / wt.\%

\begin{tabular}{|c|c|c|c|c|c|c|c|c|c|c|c|c|}
\hline $\mathbf{N i}$ & Co & Mo & $\mathrm{Cr}$ & Al & C & $\mathbf{T i}$ & Mn & $\mathbf{F e}$ & $\mathbf{S i}$ & $\mathbf{S}$ & $\mathbf{C u}$ & B \\
\hline $\begin{array}{l}44.5 \\
\min \end{array}$ & $\begin{array}{l}10- \\
15\end{array}$ & $\begin{array}{l}8- \\
10\end{array}$ & $\begin{array}{l}20 \\
- \\
24\end{array}$ & $\begin{array}{l}0.8 \\
- \\
1.5\end{array}$ & $\begin{array}{l}0.05 \\
- \\
0.15\end{array}$ & $\begin{array}{l}0.6 \\
\max \end{array}$ & $\begin{array}{l}1.0 \\
\max \end{array}$ & $\begin{array}{l}5 \\
\max \end{array}$ & $1 \max$ & $\begin{array}{l}0.0015 \\
\max \end{array}$ & $\begin{array}{l}0.5 \\
\max \end{array}$ & $\begin{array}{l}0.006 \\
\max \end{array}$ \\
\hline
\end{tabular}

Table 2. Details of the oxidation conditions studied.

\begin{tabular}{|l|l|l|l|}
\hline $\begin{array}{l}\text { Exposure } \\
\text { Temperature }\left({ }^{\mathbf{}} \mathbf{C}\right)\end{array}$ & $\begin{array}{l}\text { Environmental } \\
\text { Conditions }\end{array}$ & Number of Samples & $\begin{array}{l}\text { Range of Exposure } \\
\text { Times (h) }\end{array}$ \\
\hline 700 & $100 \%$ steam & 6 & $100-4000$ \\
\hline 750 & $100 \%$ steam & 5 & $100-3000$ \\
\hline 750 & $50 \%$ steam + 50\% argon & 5 & $100-3000$ \\
\hline 750 & Atmospheric air & 5 & $100-3000$ \\
\hline
\end{tabular}

In order to produce the appropriate exposure conditions in steam (carried out at the National Physical Laboratory), water was initially purified and de-aerated by first boiling from a de-ionised external reservoir, condensing through a still and subsequently stored in metallic containers under a $\mathrm{N}_{2}$ positive pressure. The purified water was then introduced into the end of a tube furnace, gasifying on contact and flowing over the samples before exiting through a bubbler at the far end of the furnace. The level of dissolved oxygen in the steam was of the order of $150 \mathrm{ppb}$. For the $100 \%$ steam exposures, liquid water was introduced to the end of the furnace at a rate of $0.1472 \mathrm{ml} \mathrm{min}^{-1}$. For the $50 / 50 \%$ steam/argon gas mixture, liquid water and gaseous argon were introduced at a rate of 0.0736 $\mathrm{ml} \mathrm{min}^{-1}$ and $100 \mathrm{ml} \mathrm{min}{ }^{-1}$ respectively at room temperature and atmospheric pressure to produce the 
required gas composition by volume. The samples oxidised in air were placed in ceramic crucibles in a standard laboratory furnace. The furnace for the dry samples was subject to minor periodic cooling when samples were removed, resulting in a temperature drop of approximately $30^{\circ} \mathrm{C}$. After oxidation the samples were removed, allowed to cool in air, and subsequently nickel plated to protect the oxide layer.

The analytical equipment used in this investigation included a Carl Zeiss (LEO) 1530VP FEGSEM with an EDAX Pegasus EDS system, a JEOL 2000FX thermionic tungsten filament TEM and an FEI Nova Nanolab S600 Dual Beam FIBSEM. The samples were cross-sectioned using a diamond cutting wheel, mounted in conductive Bakelite and polished first with diamond paste to a $1 \mu \mathrm{m}$ finish and then subsequently using alkaline based $0.05 \mu \mathrm{m}$ colloidal silica.

Scale thickness measurements were performed on SEM micrographs by tracing a line along the top and bottom boundary of the scale and taking an average of the distance between the lines using the software package Image-Pro Plus 5.0. This procedure was repeated on nine randomly spaced micrographs and an average of these distances was then determined for each sample. The standard error in the thickness measurements was then calculated based on $95 \%$ confidence intervals.

Voids observed within the first few micrometers of the surface were quantified using two methods. The first method was performed similarly to the scale thickness measurements and involved averaging the two dimensional area of void space over nine randomly spaced micrographs on a single sample cross-section. The second, more sophisticated, method involved a slice by slice image reconstruction which produced a 3D representation of the oxide scale and underlying microstructure. To create an accurate $3 \mathrm{D}$ reconstruction requires the use of a dual beam FIB/SEM system. The FIB was used to remove consecutive slices of the volume of interest, each slice being $\sim 50 \mathrm{~nm}$ thick. The SEM was then used to image the newly exposed faces. In total 200 slices were imaged. The images were optimised for contrast between each phase to aid in the reconstruction of the volume. The reconstruction was performed using Avizo ${ }^{\circledR}$ Standard software into which the image files were imported, together with the dimensions of the volume. The images were then subsequently aligned 
using the built-in Avizo alignment algorithm. Once the images were aligned it was possible to associate a particular range of intensities to each phase being reconstructed, allowing for volume and position to be assigned to a particular phase. Care had to be taken when designating space associated with the voids specifically due to the inherent difficulties of imaging where material was not present. The three phases reconstructed were the external scale, the internal oxide precipitate and the void space. The volume of void space could then be calculated from the reconstructed image. This 3D reconstruction method was also employed to investigate the growth morphology of the internal oxide precipitate.

\section{Results}

\subsection{Scale Morphology}

IN617 contains equiaxed grains ranging in size from 50 to $100 \mu \mathrm{m}$, with numerous annealing twins, within the bulk microstructure. Sample preparation, in this case grinding to 600 grit, results into a region of surface damage which, upon exposure to the oxidising environment, recrystallises into a region with a much finer grain size and a higher density of twin boundaries than the bulk alloy.

(a)

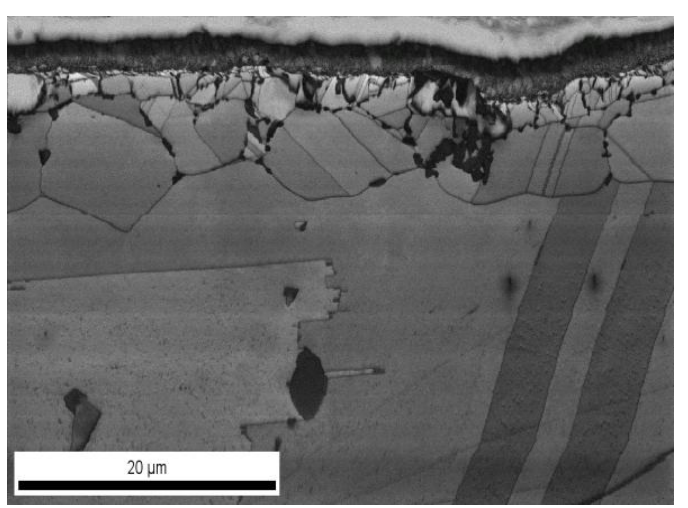

(b)

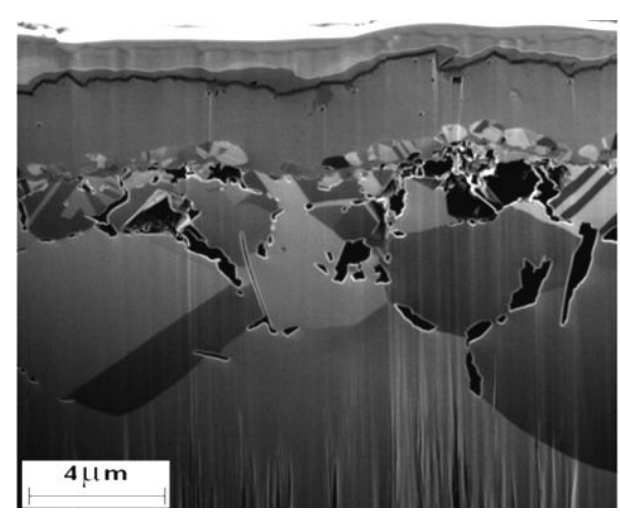

Figure 1. Micrographs showing the fine grained recrystallised region of the alloy immediately beneath the oxide scale. a) An EBSD image quality map of a cross sectioned sample oxidised at $750^{\circ} \mathrm{C}$ for $3000 \mathrm{~h}$ in $50 / 50 \%$ steam/argon. b) FIB image of ion milled sample oxidised at $750^{\circ} \mathrm{C}$ for $3000 \mathrm{~h}$ in $50 / 50 \%$ steam/argon.

This ground surface finish is representative of components which have been machined before entering service, and the subsurface microstructure can affect the internal oxidation morphology. Figure 1 illustrates the existence of a surface grain structure which is significantly finer than the bulk alloy.

The key features of the oxidation process of IN617 are highlighted in Figure 2. All of the samples oxidised in the presence of steam showed the presence of a continuous and compact oxide, as shown 
in Figure 2. Chemical analysis using EDX performed on thin foil samples in the TEM (see Table 3) indicated that the continuous oxide scale, which formed on samples exposed in steam, contains primarily chromium and oxygen, consistent with it being chromia, with a moderate enrichment of titanium. The internal oxide, however, was rich in aluminium and oxygen, consistent with alumina.

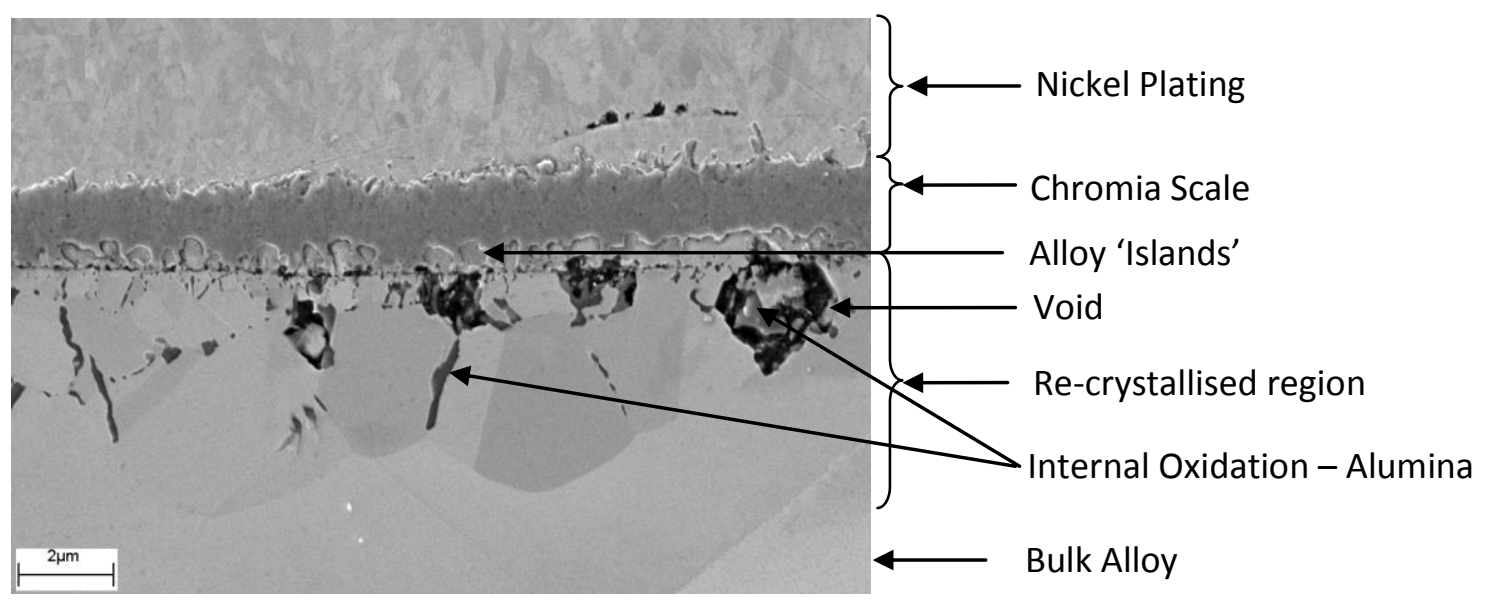

Figure 2. SEM micrograph showing the main features of oxidation in a cross sectioned sample of IN617 oxidised at $700^{\circ} \mathrm{C}$ for 3000 h $100 \%$ steam.

Figure 3 shows a typical SEM image from a cross-sectioned sample, in this case exposed to steam at $750^{\circ} \mathrm{C}$ for $3000 \mathrm{~h}$, and an EDX line scan which shows the presence of chromium and oxygen peaks at the outer surface corresponding to the scale, with some evidence for the enrichment of titanium, and two localised increases in the aluminium peak intensity as the probe intersects regions of internal oxidation. In order to avoid problems with beam overlap, the results from EDX in the SEM were corroborated by measurements from a thin foil sample in the TEM, as shown in Table 3. The internal oxide was also analysed by selected area electron diffraction and was positively identified as alumina. These findings are consistent with previous observations concerned with the oxidation of IN617 under different conditions $[5,6]$. 

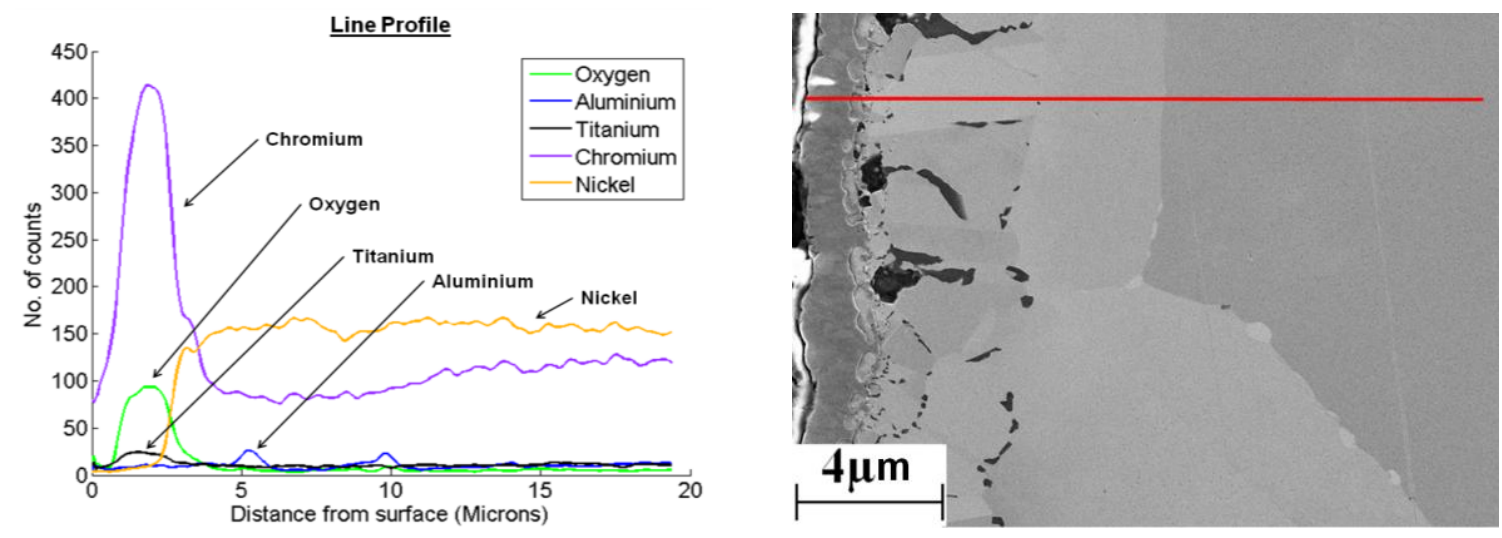

Figure 3. EDX line scan showing the depth profile of elemental abundance in a cross sectioned sample oxidised at $750^{\circ} \mathrm{C}$ for $3000 \mathrm{~h}$ in 50/50\% steam/argon. This line scan is typical of all samples oxidised in the presence of both 100\% and 50\% steam after $3000 \mathrm{~h}$. An attempt had been made to avoid features such as internal precipitates and voids in the scan.

Differences were, however, observed between oxidation in the three environments, as illustrated in Figure 4, which compares the microstructures observed in air, 100\% steam and 50\%/50\% steam/argon after $3000 \mathrm{~h}$ at $750^{\circ} \mathrm{C}$, and in $100 \%$ steam at $700^{\circ} \mathrm{C}$ for the same time. The samples exposed in steam always had a continuous chromia layer even at the shortest oxidation period of $100 \mathrm{~h}$, with no sign of a transient oxide. In general, the chromia layer was reasonably uniform in the samples exposed to steam, however, there were small localised regions of reduced oxide scale thickness coinciding with irregular alloy/scale boundaries. The samples oxidised in air, however, often had a multi-layered oxide consisting of a cobalt-chromium rich oxide on the outer most region followed by a nickel-cobalt oxide and finally a chromia layer at the alloy/scale boundary. The outer layers in the samples exposed in air had a tendency to occasionally spall off on cooling of the sample. The dry oxidation samples showed the greatest variation in both total and chromium oxide thicknesses.

The irregular nature of the alloy/scale boundary can be seen in Figures 2 and 4, together with a tendency for the scale to envelope small 'islands' of the alloy matrix, approximately $1 \mu \mathrm{m}$ in diameter. These islands, although also seen in the air oxidised sample, were notably more common in the steam oxidised samples and were confined to the inner most side of the scale. 3D reconstruction of the oxidation region showed these islands to, in fact, be connected to the bulk alloy with a high degree of interconnectivity. Thin foil EDX analysis in the TEM showed these islands to have similar composition to the matrix, except for a significant reduction in aluminium content. 
(a) Atmospheric air at $750^{\circ} \mathrm{C}$ for $3000 \mathrm{~h}$

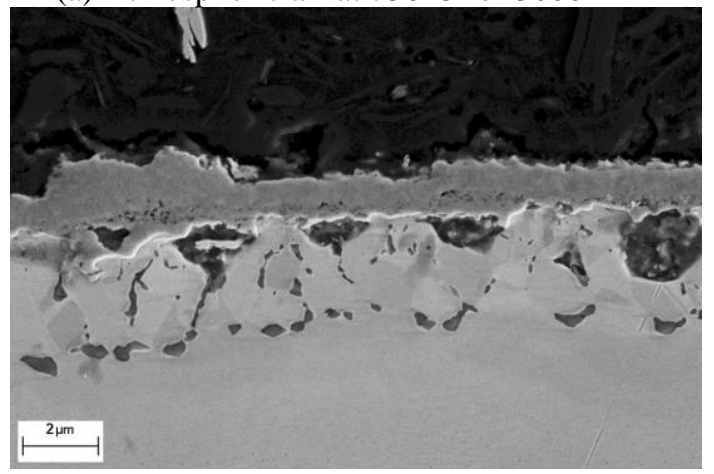

(c) $50 / 50 \%$ Steam/argon at $750^{\circ} \mathrm{C}$ for $3000 \mathrm{~h}$

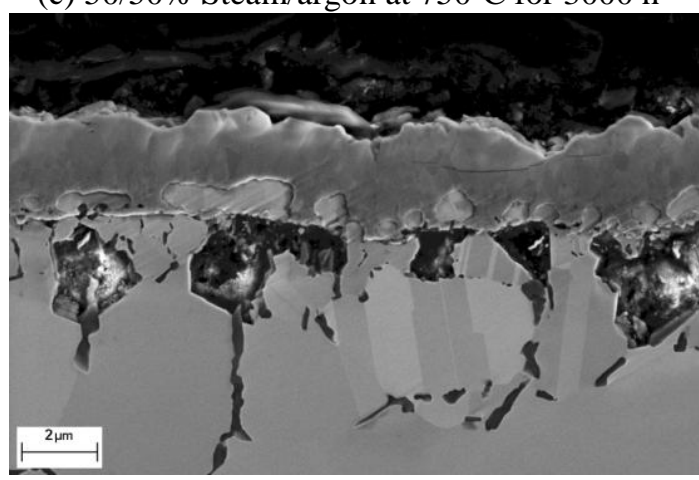

(b) $100 \%$ Steam at $700^{\circ} \mathrm{C}$ for $3000 \mathrm{~h}$

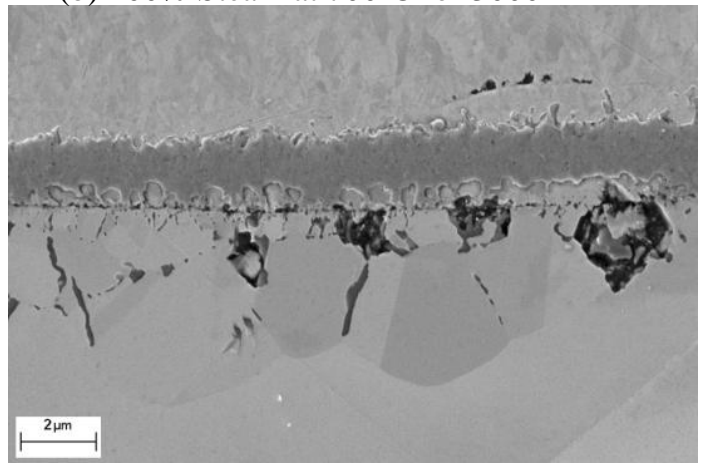

(d) $100 \%$ Steam at $750^{\circ} \mathrm{C}$ for $3000 \mathrm{~h}$

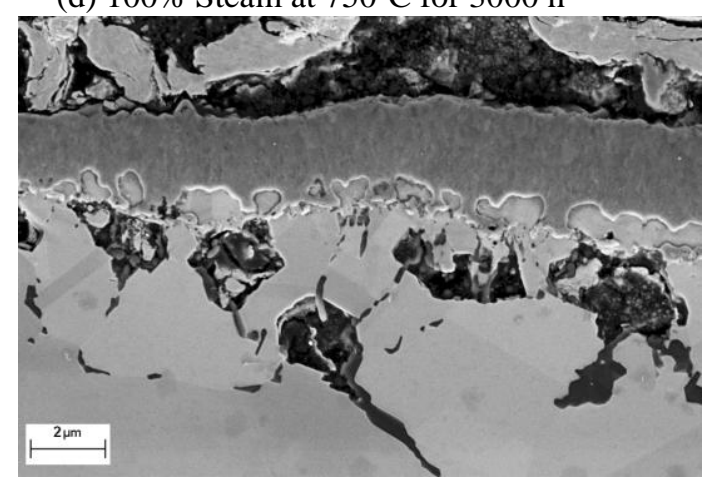

Figure 4. Cross-section SEM images showing scale thickness and internal oxidation region after exposure at a) $750^{\circ} \mathrm{C}$ for $3000 \mathrm{~h}$ in air, b) $700^{\circ} \mathrm{C}$ for $3000 \mathrm{~h}$ in $100 \%$ steam, c) $750^{\circ} \mathrm{C}$ for $3000 \mathrm{~h}$ in $50 / 50 \%$ steam/argon and d) $750^{\circ} \mathrm{C}$ for $3000 \mathrm{~h}$ in $100 \%$ steam.

\subsection{Oxidation Kinetics}

The mean scale thickness was determined for each sample, and the results are plotted in Figure 5 as a function of the square root of time. It can be seen that there is an increase in scale thickness with increasing temperature by comparison of the samples aged at $700^{\circ} \mathrm{C}$ and $750^{\circ} \mathrm{C}$ in the $100 \%$ steam atmosphere. However, it was observed in both cases that a simple linear behaviour was not observed for the samples aged in $100 \%$ steam. There is an indication that in the samples oxidised for the shorter periods of time, the $100 \%$ steam samples showed a greater average scale thickness, than those in $50 \% / 50 \%$ steam/argon or air. Therefore, it is considered that a better fit to the data can be made by considering two different rate constants for the initial and later stages of oxidation, with the change between the two occurring at a slightly shorter time at the higher temperature. However, the samples exposed in both $50 \% / 50 \%$ steam/Ar and air, did appear to show a linear relationship, indicating that they were not subject to the initial acceleration of oxidation kinetics as the samples exposed in $100 \%$ steam. 


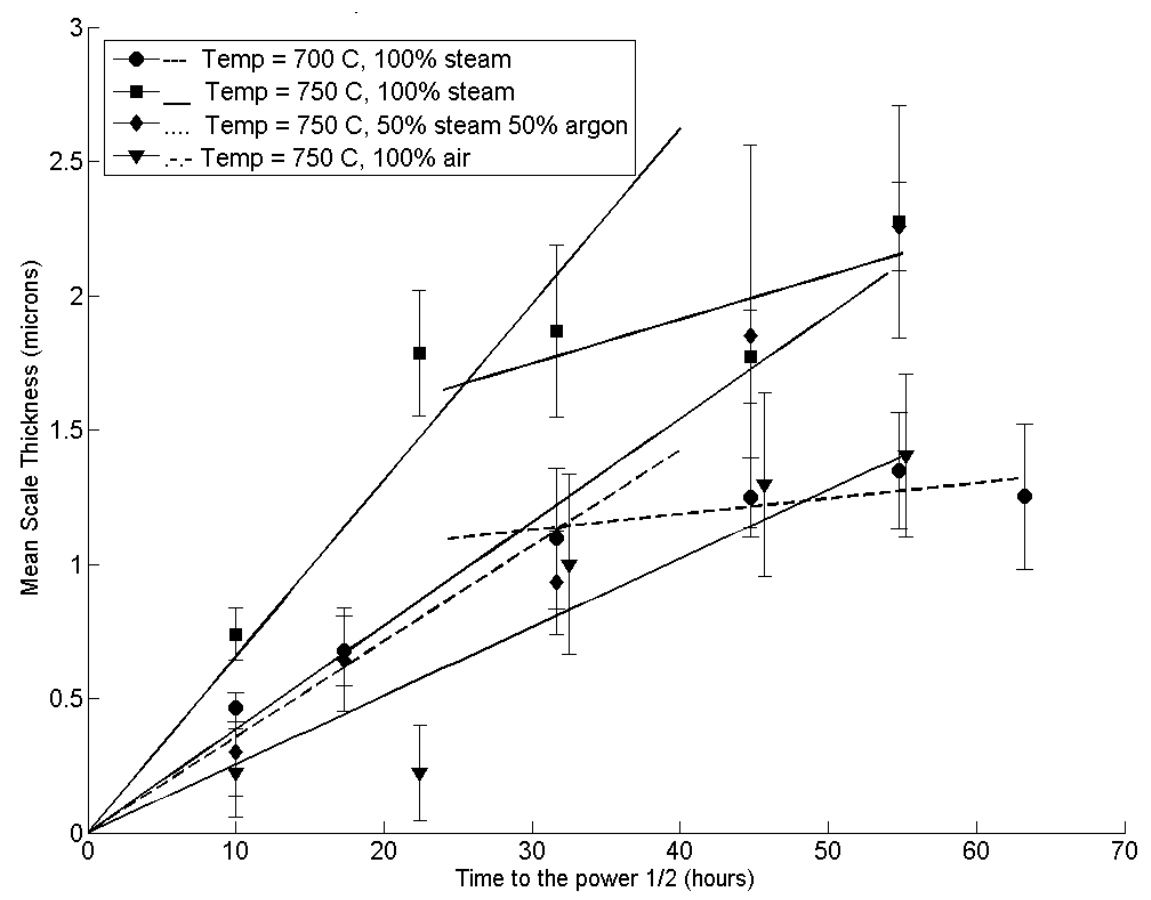

Figure 5. Graph showing the mean scale thickness plotted against time to the power of a half. The error bar is calculated based on $95 \%$ confidence.

\subsection{Internal Oxidation Morphology}

The internal oxidation observed in Figure 4 was investigated in more detail using tomography methods and a 3D reconstruction of the oxide structure using a slice by slice image reconstruction method can be seen in Figure 6. The reconstruction allows for better visualisation of the oxidation morphology, showing features only discernable using 3D methods. The complex nature of the scale/alloy interface is clearly visible, with an apparent intricate mechanical interlocking between the oxide scale and the alloy, resulting in the appearance of 'islands' of alloy matrix within the oxide scale on cross-sectioned samples. Reconstruction of the alumina clearly illustrates that it is forming along the grain boundaries, as evidenced in the reconstruction volume by the alumina around the perimeter of grains and advancing into the alloy as interconnected plates. It was also noted that the alumina which formed closer to the alloy/scale boundary tended to be reduced in size, mirroring the smaller grains closer to the surface, compared to that extending deeper into the alloy around the boundaries of the larger grains. The reconstruction also clearly shows the high level of interconnectivity exhibited by the internal, inwardly growing, alumina. 

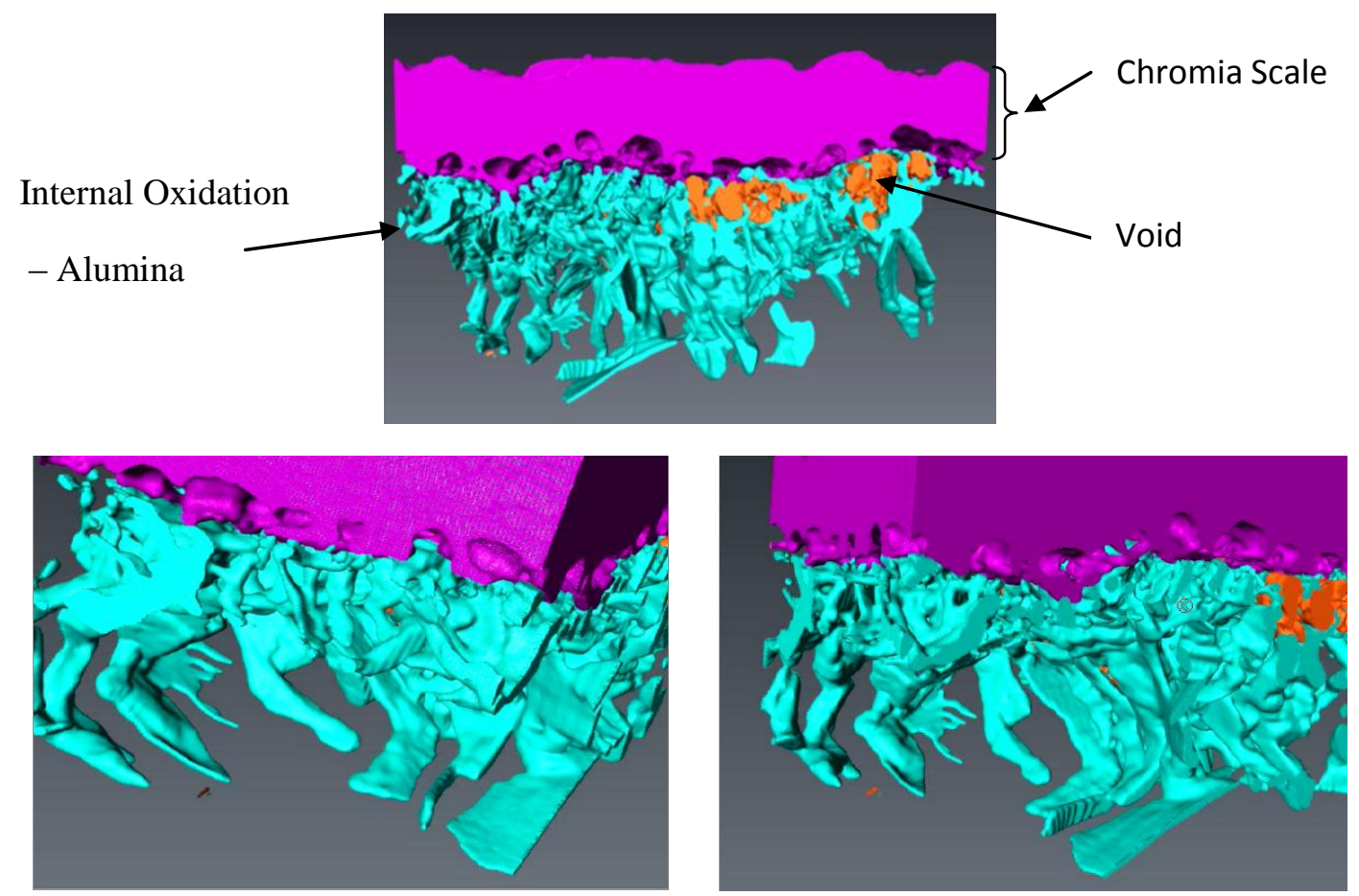

Figure 6. A slice by slice 3D reconstruction of the chromia scale (pink), internal alumina (light blue) and internal voids (orange). Reconstructed from images taken from sample at $750^{\circ} \mathrm{C}$ for $3000 \mathrm{~h}$ exposed in $50 / 50 \%$ steam/argon.

\subsection{Void Morphology}

The presence of voids was also a prominent feature of the sub-surface morphology, and they were found to appear in samples after as little as $100 \mathrm{~h}$ ageing, and were often associated with large and deeply penetrating regions of internal oxidation. The air oxidised samples showed a clear difference in void characteristics when compared to the steam oxidised samples. In general, the voids that formed in atmospheres containing steam at $750^{\circ} \mathrm{C}$ were larger in extent than those in the air exposed samples, as shown in Figure 4. Figure 7 illustrates voids in the air oxidised samples, which were observed to form mainly at the alloy/scale boundary and along alloy grain boundaries. The voids that formed on grain boundaries were associated with intergranular oxidation of aluminium and chromium and appeared to form discontinuously in cross-section and penetrate far deeper into the alloy than the internal alumina, which was not associated with these deeply penetrating voids. The voids in the steam oxidised samples formed at a greater volume density than in the dry oxidation samples but were confined to the oxidation region near the surface, never penetrating deeper than the internal alumina. These voids can be seen in detail in Figure 8 . The voids in the steam oxidation samples did not, in general, appear to form on the alloy/scale boundaries but were instead slightly embedded in the alloy matrix, and almost always were found to be surrounded by alumina. 
(a)

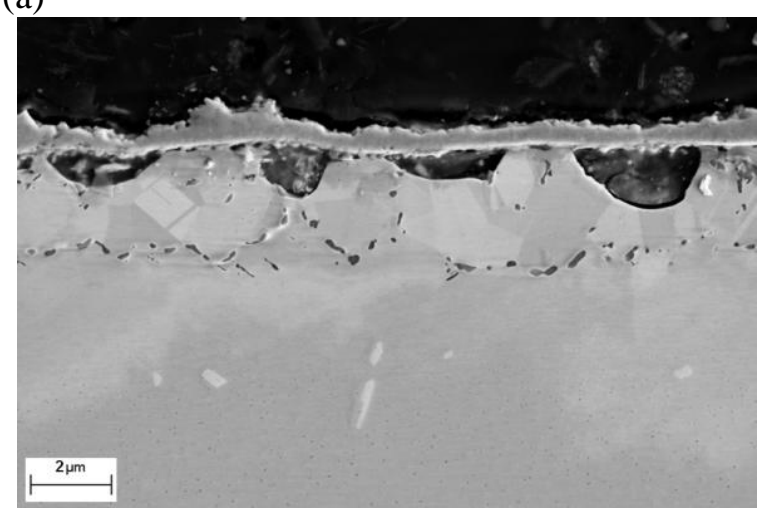

(b)

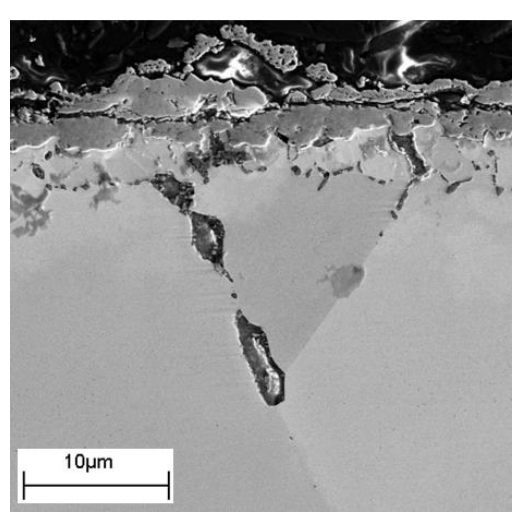

Figure 7. Micrographs showing void formation on IN617 oxidised at $750^{\circ} \mathrm{C}$ in atmospheric air (a) void growth on alloy/scale boundary and $(b)$ deeply penetrating void growth along grain boundaries.

In order to examine the internal structure of the voids in more detail, a sample was milled with an ion beam within a FIBSEM system. Figure 8a illustrates an example of a void which occurs within the first 2 to $10 \mu \mathrm{m}$ of the surface of the steam oxidised samples. It can be seen that a complex internal structure exists within the voids. After milling a section to expose a void, a thin foil sample was additionally lifted out to facilitate chemical analysis in the TEM; this is illustrated in Figure 9 and the EDX data presented in Table 3. The internal 'fibrous' structure of the void has been identified using selected area electron diffraction combined with EDX to be alumina. Although the voids are usually associated with internal alumina, alumina is not necessarily associated with the voids. In addition, the volume density of the voids has been quantified and presented in Figure 8b. It can be seen that the void volume increases with temperature, and furthermore that the presence of steam appears to enhance the void density significantly.

(a)

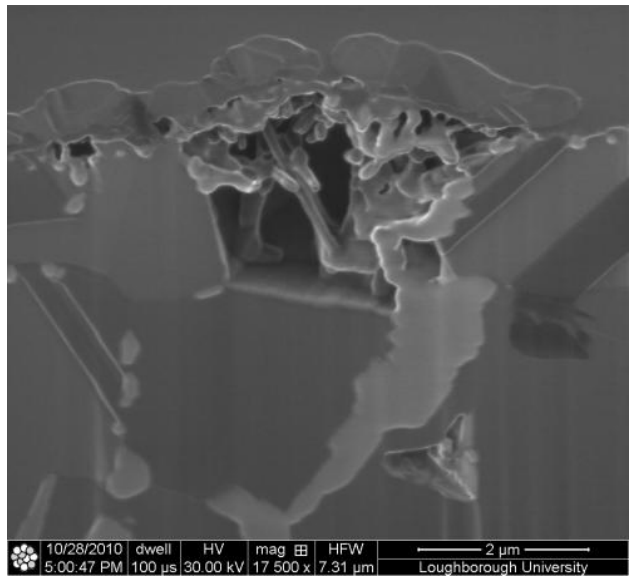

(b)

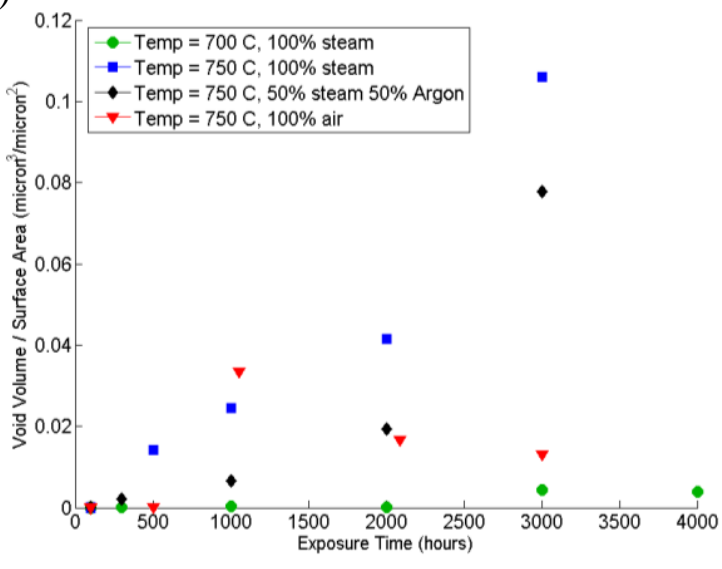

Figure 8. (a) FIB image of an ion milled cross-section showing a void and internal structure in the sample oxidised at $750^{\circ} \mathrm{C}$ for $3000 \mathrm{~h}$ in 50/50\% steam/argon. The large particle associated with the void is alumina. (b) Graph illustrating the void volume as a function of time in the samples aged in the 100\% steam and 50/50\% steam/argon atmospheres. 


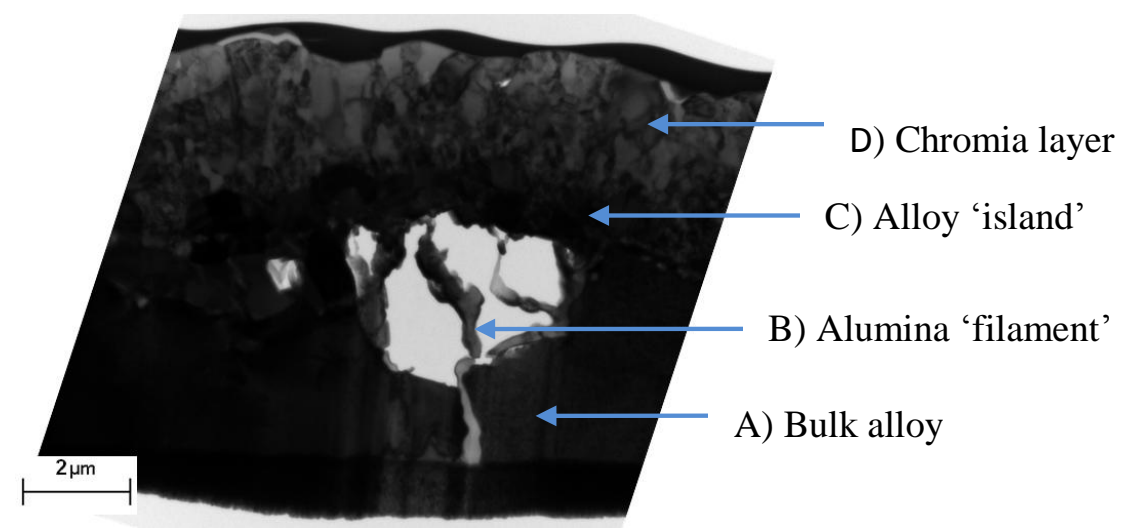

Figure 9. Thin foil TEM sample of the oxide scale, internal oxide and voids on a sample of IN617 exposed to steam at $750^{\circ} \mathrm{C}$ for $3000 \mathrm{~h}$.

Table 3. Chemical composition data obtained using EDX analysis from a thin foil TEM sample extracted using a FIBSEM, as illustrated in Figure 9. Units are in wt.\%.

\begin{tabular}{|l|l|l|l|l|l|l|l|l|l|}
\hline $\begin{array}{l}\text { Element/ } \\
\text { Position }\end{array}$ & $\mathbf{O}$ & $\mathbf{A l}$ & $\mathbf{T i}$ & $\mathbf{C r}$ & $\mathbf{M n}$ & $\mathbf{F e}$ & $\mathbf{C o}$ & $\mathbf{N i}$ & $\mathbf{M o}$ \\
\hline A & - & 0.3 & 0.1 & 17.7 & - & 1.1 & 13.6 & 60.1 & 11.3 \\
\hline B & 43.1 & 51.3 & 0.4 & 0.4 & - & - & 0.1 & 0.2 & 0.4 \\
\hline C & - & 0.1 & 0.2 & 18.3 & 0.5 & 0.2 & 15.7 & 65.7 & 14.4 \\
\hline D & 37.8 & 0.2 & 1.5 & 65.6 & 1.0 & 0.3 & 0.5 & 2.6 & 0.4 \\
\hline
\end{tabular}

Within the thin foil sample extracted from a void exposed by ion beam milling, positions A and C had compositions representative of the bulk alloy, whereas position $\mathrm{B}$, which is from one of the oxide fingers within the internal structure of the void, had a composition consistent with alumina. Position D illustrates that the outer oxide scale comprised of chromia.

\section{Summary}

The samples used in this research had a ground surface finish, representative of a machined component entering service. It has been observed that the presence of cold work may affect the oxidation kinetics via the formation of smaller grains towards the outer surface, and therefore in turn increasing the number of grain boundaries which can act as sites for enhanced diffusion.

The outer oxide scale on the samples exposed in environments containing steam comprised of chromia, with some evidence for enrichment in titanium. 'Islands' of the composition of the bulk alloy were also observed within the scale, indicative of an inward growth, as previously observed in Ni-Cr-Al alloys [7, 8]. However, the samples exposed in air exhibited a multi-layered scale comprising of an outer region rich in $\mathrm{Co}$ and $\mathrm{Cr}$, a middle layer rich in $\mathrm{Ni}$ and $\mathrm{Co}$, and then an inner 
chromia layer. Measurement of the thickness of the oxide scales demonstrated that scale thickness increased with temperature, as expected. However, there was some evidence of an acceleration in the oxidation rate in the early stages of ageing in steam containing environments compared to air. After $3000 \mathrm{~h}$ ageing little difference was observed in the oxide thicknesses of samples exposed in either $100 \%$ steam or $50 / 50 \%$ steam/argon mixtures, although both were approximately double the oxide thickness measured on the sample exposed in air.

Significant internal oxidation was observed, identified as alumina. A full 3D reconstruction using FIBSEM clearly showed that the alumina followed the grain boundaries, forming as interconnected plates in 3D. There was also a high degree of mechanical interlocking between the scale and the alloy substrate. A significant number of voids were also observed in all samples, with some differences in the void amount, location and morphology between the different environments. The measured void volume was much greater in the samples exposed in steam compared to those in air. In the samples exposed in steam, the voids were associated with large and deeply penetrating regions of internal oxidation. Ion beam milling revealed that the voids had an internal structure, which comprised of alumina 'filaments', and that the voids were also generally surrounded by a layer of alumina.

\section{Acknowledgements}

We would like to acknowledge financial support from both EPSRC (Grant No. EP/G037345/1) through the Doctoral Training Centre in Efficient Fossil Energy Technologies and Alstom Power Ltd. 


\section{References}

1. N. Birks, G. H. Meier and F. S. Pettit, Introduction to the high-temperature oxidation of metals, 2nd edition, Cambridge University Press, 2006.

2. D. Young, High Temperature Oxidation and Corrosion of Metals, Elsevier, 2008.

3. I. Wright and R. Dooley, 'A review of the oxidation behaviour of structural alloys in steam', International Materials Reviews, (2010), 129-167.

4. S. Saunders, M. Monteiro and F. Rizzo, 'The oxidation behaviour of metals and alloys at high temperatures in atmospheres containing water vapour: A review', Progress in Materials Science, (2008), 775-837.

5. D. Kim, C. Jang and W. Ryu, 'Oxidation Characteristics and Oxide Layer Evolution of Alloy 617 and Haynes 230 at 900 degrees C and 1100 degrees C', Oxidation of Metals, (2009), 271-293.

6. C. Jang, D. Lee and D. Kim, 'Oxidation behaviour of an Alloy 617 in very high-temperature air and helium environments', International Journal of Pressure Vessels and Piping, (2008), 368-377.

7. F. H. Stott, G. C. Wood, Y. Shida, D. P. Whittle and B. D. Bastow, 'The development of internal and intergranular oxides in nickel-chromium-aluminium alloys at high temperature', Corrosion Science, 21 (1981), 599-624.

8. F. I. Wei and F. H. Stott, 'The influence of aluminium on the oxidation of a $\mathrm{Cr}_{2} \mathrm{O}_{3}$-forming nickelchromium alloy', Reactivity of Solids, 6 (1988), 129-144. 